\title{
Grassroots innovations in community energy: The role of intermediaries in niche development
}

\author{
Tom Hargreaves ${ }^{\mathrm{a}, *}$, Sabine Hielscher ${ }^{\mathrm{b}}$, Gill Seyfang ${ }^{\mathrm{a}}$, Adrian Smith ${ }^{\mathrm{b}}$ \\ a Science, Society and Sustainability Research Group (3S), School of Environmental Sciences, University of East Anglia, Norwich NR4 7TJ, UK \\ ${ }^{\mathrm{b}}$ Science and Technology Policy Research Unit (SPRU), University of Sussex, Brighton BN1 9QE, UK
}

\section{A R T I C L E I N F O}

\section{Article history:}

Received 21 August 2012

Received in revised form 14 February 2013

Accepted 17 February 2013

\section{Keywords:}

Strategic niche management

Intermediary actors

Grassroots innovation

Community energy

\begin{abstract}
A B S T R A C T
Community energy projects are attracting increasing attention as potential sources of innovation to support sustainable energy transitions. Research into 'grassroots innovations' like community energy often recognises the difficulties they face in simply surviving let alone in growing or seeding wider change. Strategic niche management theory is potentially helpful here as it highlights the important roles played by 'intermediary actors' in consolidating, growing and diffusing novel innovations. This paper presents the first in-depth analysis of intermediary work in the UK community energy sector. New empirical evidence was gathered through interviews with 15 community energy intermediaries and a content analysis of 113 intermediary-produced case studies about community energy projects. Analysis finds intermediaries adopting a variety of methods to try and diffuse generic lessons about contextspecific projects, but that trying to coordinate support for local projects that exist amidst very different social and political circumstances is challenging. This is exacerbated by the challenges of building a coherent institutional infrastructure for a sector where aims and approaches diverge, and where underlying resources are uncertain and inconsistent. Applications of relatively simple, growth-oriented approaches like strategic niche management to grassroots innovations need to be reformulated to better recognise their diverse and conflicted realities on the ground.
\end{abstract}

(c) 2013 Elsevier Ltd. All rights reserved.

\section{Introduction}

Realising a sustainable society is increasingly seen as demanding a fundamental transition in the way a whole range of different societal functions - from energy to water and from food to mobility - are met (Elzen et al., 2004). Whilst scholars working in the field of innovation studies have increasingly come to see novel innovations emerging from small-scale and relatively protected 'niches' (Geels, 2005), to date, the majority of this work has focused on market-based innovations designed for competitiveness, rather than more novel socio-technical alternatives emerging from civil society activism on sustainability (Smith et al., 2010).

In this context, an emerging body of work has come to focus on radical 'grassroots innovations' - those that challenge and often attempt to replace existing and unsustainable sociotechnical systems - as an arena that might be developed (Seyfang and Smith, 2007). At the same time, however, whilst many community activists and increasingly policy makers, seek to promote their growth and diffusion, much of the existing work on grassroots

\footnotetext{
* Corresponding author. Tel.: +44 01603 593116; fax: +44 01603593739

E-mail address: tom.hargreaves@uea.ac.uk (T. Hargreaves).
}

innovations has identified the significant difficulties they face in simply surviving, let alone in having a substantial influence over wider unsustainable systems.

In trying to understand how grassroots innovations might overcome these challenges, we focus in this paper on the roles played by 'intermediary' actors in the grassroots innovation process. Within the literature on niches, intermediaries are identified as playing a number of important roles in helping niches to develop and become more robust (Geels and Deuten, 2006). Specifically, intermediaries connect specific and often isolated local innovation projects with one another and with the wider world (Howells, 2006). Through this 'relational work' (Moss, 2009) they are able to identify common issues and problems encountered across multiple local projects, and can therefore support niche development and diffusion by sharing this knowledge more widely, helping subsequent projects to benefit from accumulated experience.

To date, however, very little work has examined the role of intermediaries in sustainability niches and still less has examined the nature and extent of the roles they may play in helping grassroots innovations to develop and grow. Such development and growth is an important issue and one that is increasingly sought by policy makers and by many community activists. At the 
same time, not all grassroots innovations do wish to grow and diffuse and it is therefore important to be critical of policy goals as well as analytical approaches that seek to simplify and standardise this highly diverse field. With these concerns in mind, our paper focuses on how intermediary actors engage with the diverse forms of grassroots innovation being developed within the field of community energy in the UK - a field that has received a great deal of policy attention in recent years because, if growth and diffusion could be achieved, it has the potential to make a substantial contribution to tackling current energy challenges (e.g. Walker et al., 2007). Examples of community energy intermediaries include the Centre for Sustainable Energy; or, operating on a more regional basis, Community Energy Scotland. Both help to initiate new community energy projects, provide training and advice to practitioners, and undertake research and policy analysis on community energy making this available to local projects.

Section 2 introduces the literature on grassroots innovations, niches and intermediaries more broadly, before Section 3 outlines the UK community energy sector and the methodological approach adopted in this study. Drawing on interviews with 15 intermediary actors working within UK community energy, as well as a content analysis of 113 case studies produced by intermediary actors about local community energy projects, Section 4 then details the different roles played, and challenges faced, by intermediaries working in this area. Finally, Section 5 draws some conclusions for future research on and theorising about grassroots innovations.

\section{Intermediaries and grassroots innovation}

Seyfang and Smith highlight the 'grassroots' as "a neglected site of innovation for sustainability" (Seyfang and Smith, 2007, p. 585). Understanding 'grassroots' to refer to initiatives undertaken by committed activists within civil society arenas, they highlight a number of important ways in which grassroots innovations differ from the more mainstream, market-based innovations that, to date, have been the mainstay of both empirical research and theoretical development in innovation studies (Geels, 2005). These differences include: distinct organisational forms (firms vs. a wide range of organisational types encompassing co-ops, voluntary associations, informal community groups etc.); different resource bases (commercial income vs. voluntary labour, grant funding etc.); divergent contextual situations (the market economy vs. the social economy); alternative driving motivations (the pursuit of profit vs. meeting social needs or pursuing ideological commitments); and the pursuit of qualitatively different kinds of sustainable development (mainstream business greening vs. radical reform of sociotechnical systems) (Seyfang and Smith, 2007, p. 592). It is the nature of these differences, the fact that grassroots innovations exist in spaces where 'the rules are different' from (and at times oppositional to) the mainstream, that makes grassroots innovations a profoundly interesting and challenging site for the application and development of nichebased innovation theories.

Since Seyfang and Smith's work, a growing number of studies have examined how various kinds of grassroots organisations are either seeking to influence innovation processes from the outside (e.g. Elzen et al., 2011; Geels and Verhees, 2011), or are actively engaged in innovation processes themselves. For example, recent studies have looked at grassroots innovations in eco-housing and eco-villages (Avelino and Kunze, 2009; Seyfang, 2009; Smith, 2007); complementary currencies (Longhurst, 2012) organic and local food systems (Smith, 2006a); and energy (Geels and Verhees, 2011; Hielscher et al., 2013). Common across many of these case studies, however, is the identification of the profound difficulties grassroots innovations face even in simply surviving in the medium to longer term, let alone in growing, diffusing or challenging mainstream systems.

Seyfang and Smith categorise these challenges into two forms (Seyfang and Smith, 2007). Intrinsic challenges refer to internally focused issues of how grassroots innovations are organised and managed, the skills and resources they require, and the ways in which this can leave them vulnerable to wider shocks, such as funding cuts, loss of key people, or changes in policy priorities. By contrast, diffusion challenges refer to the many and various barriers that work to reduce the wider, external influences that grassroots innovations may have. These can include context-specificity and 'geographical rootedness', ideological commitments to being 'other' and outside the mainstream, competition from more powerful mainstream groups who may develop watered-down alternatives, and the general risk aversion of policy makers when dealing with small-scale, often radical, and relatively informal innovating organisations.

Whilst the precise challenges will inevitably differ from case to case, in attempting to understand how grassroots innovations in general may be helped to survive for longer and, should they or policy makers and intermediaries so desire, to diffuse and grow, we turn to developments in niche theories (e.g. Kemp et al., 1998; Hoogma et al., 2002; Hegger et al., 2007; Raven, 2007) as offering some potentially helpful theoretical tools. Specifically, strategic niche management is a theory of how innovations develop and grow and how those processes can be harnessed strategically so as to challenge and potentially replace existing sociotechnical systems. To be clear, whilst it is far from the case that all grassroots innovations necessarily wish to scale-up, grow or diffuse, the application of niche theories is potentially extremely valuable for those that do, as well as for normative policy goals in this area and, accordingly, has attracted considerable recent attention (e.g. Kemp et al., 2001; Truffer, 2003; Smith, 2006a, b; and see Smith et al., 2010 for a review). Here, and like grassroots innovations, niche theories emphasise that the status quo of incremental efficiency improvements and business greening will no longer do and that more fundamental changes - whether in technologies and infrastructures or in social norms, values and institutions - are required.

Within the niche theory literature, a number of key factors have been identified, often through analysis of historical case studies, as important in facilitating the development of robust and successful niches. Smith and Raven et al., for example, highlight the importance of various forms of learning, networking between stakeholders, the development of institutions to promote the niche innovation, and the ways in which niche innovations might be translated to fit-in with mainstream systems (Smith, 2007; Raven et al., 2010). In this paper, however, we have chosen to focus on one key factor that has hitherto been largely neglected - intermediary actors (Geels and Deuten, 2006).

Whilst early work in niche theory tended to focus on single projects and experiments (e.g. Hoogma et al., 2002), the focus has since shifted to try and understand how lessons and experiences from across multiple local projects get exchanged and distributed to form, gradually, a shared development trajectory for the emerging innovation sector as a whole. In the terminology of niche theory, the focus has shifted from understanding 'local projects' towards understanding how multiple such projects combine to form a 'global niche' level which refers to an emerging field or community at which shared rules and practices form and evolve (e.g. Geels and Raven, 2006; Raven et al., 2008, 2010). Here, Geels and Deuten observe that global niches do not just arise spontaneously, but that this requires 'dedicated socio-cognitive work' (Geels and Deuten, 2006, p. 266) undertaken by 'intermediary actors'. 
Whilst Geels and Deuten's contribution remains one of the few papers within the niche literature to explore the role of intermediaries - perhaps partly because the niche literature is based predominantly on ex post facto case studies rather than on examining niche development in-the-making (Geels and Deuten, 2006, although see Raven, 2006; Bos and Grin, 2008) - some attention has been paid to intermediaries within the wider literature on environmental governance. In this literature, a range of different types of intermediaries have been identified, encompassing social, cultural, market, labour, knowledge, welfare and planning intermediaries (Medd and Marvin, 2008). Despite this variety, Moss highlights that their central commonality is that they all operate as 'boundary organisations' engaging in 'relational work' to connect up and bridge between different actors:

Whether facilitating dialogue, providing guidance, bridging gaps, advocating reform, or pioneering novel forms of interaction, their arenas of action are defined by their 'in-betweenness' (Moss, 2009, p. 1481).

As such, and in relation to niches specifically, intermediary actors can be broadly defined as organisations or individuals engaging in work that involves connecting local projects with one another, with the wider world and, through this, helping to generate a shared institutional infrastructure and to support the development of the niche in question.

Based on an historical case study of the development of reinforced concrete, Geels and Deuten identify three key roles for intermediary actors in niche development, each of which involves managing the flows of knowledge between local projects and the emerging global niche level. The first role relates to the 'aggregation' of knowledge from across a broad range of local projects. Here, by virtue of their ability to interface with a large number of different local projects, intermediaries are seen as uniquely placed to "compare experiences in different locations, reflect on differences and draw general conclusions" (Geels and Deuten, 2006, p. 267). The aggregation process is thus seen to involve making local knowledge 'context-free' in order that it can travel beyond its local moorings and circulate throughout the entire global niche:

'Aggregation' is the process of transforming local knowledge into robust knowledge, which is sufficiently general, abstracted and packaged, so that it is no longer tied to specific contexts. This global knowledge can travel between local practices (Geels and Deuten, 2006, p. 266-267).
The second role that Geels and Deuten highlight, involves the creation of an 'institutional infrastructure' that serves as a repository and forum for the storage, exchange and circulation of this aggregated global knowledge:

Such an infrastructure consists of forums that enable (and induce) the gathering and interaction of actors, the exchange of experiences and the organisation of collective action. Examples of such forums are conferences, seminars, workshops, technical journals, proceedings, and so on (Geels and Deuten, 2006, p. 267-268).

Finally, the third role sees a 'reversal' in the relationship and knowledge-flows between local projects and the emerging global niche. Once local experiences and lessons have been sufficiently aggregated to form a shared institutional infrastructure and emerging development trajectory for the niche as a whole, Geels and Deuten suggest that intermediaries then begin to 'coordinate' and 'frame' subsequent action on-the-ground in local projects:

A reversal occurs, in which collective knowledge repertoires at the global level become guiding for local-level activities (Geels and Deuten, 2006, p. 268).

In this final role, therefore, intermediaries come to guide the development of local activities by drawing from their aggregated global knowledge to provide advice, guidelines or even templates for how subsequent local projects should develop.

As summarised in Fig. 1, below, through these three roles - the aggregation of knowledge, the creation of an institutional infrastructure, and framing and coordinating local-level activities - intermediaries are thus seen as critical to the development of robust and successful niches that might be capable of surviving in the medium to longer term, and potentially of diffusing and scaling-up more widely.

To be clear, whilst some community activists, intermediaries and policy makers have strong aims for the growth and diffusion of particular grassroots innovations, it is far from apparent that all grassroots innovations share these normative goals. As such, whilst it is conceptually appropriate to apply strategic niche management theory to this area, it is also critical that it is applied in a way that is sensitive to the diversity and dynamism of grassroots innovations and, if necessary, that it is adapted accordingly. Nonetheless, whatever the specific aims of different local grassroots innovations, given the specific challenges they face it seems likely that intermediary actors could have an especially critical role to play in supporting them. In particular, intermediary actors seem

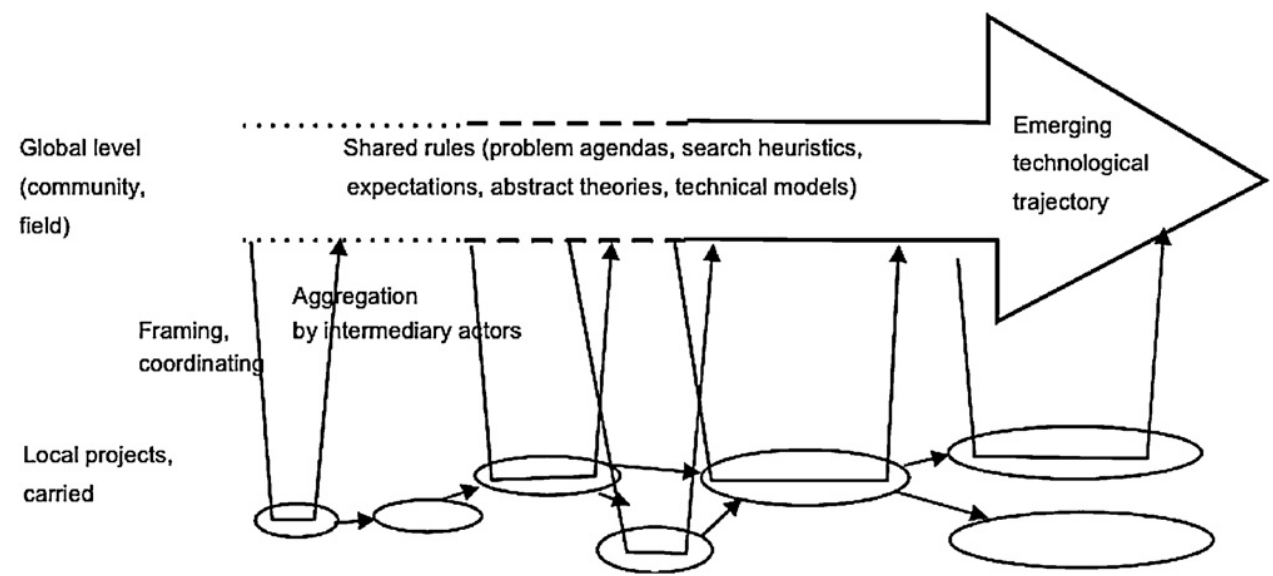

Fig. 1. Local projects and emerging technical trajectories.

Source: Geels and Deuten (2006), p. 274 
well-placed to help local grassroots innovations address both the intrinsic challenges they face, as well as the diffusion challenges that those looking to expand may encounter. For example, and as Fig. 1 suggests, even if some specific local projects fail, intermediaries might be crucial in helping the wider niche to survive and become more robust by helping others to learn from such failures. Further still, where local projects do succeed and where they wish to grow and diffuse more widely, intermediaries can potentially play an important role in publicising and building on this success in order to build interest, confidence and momentum in the niche more generally. To date, however, not only has the role of intermediaries in niche processes generally received very little empirical attention, the potentially critical role of intermediaries in grassroots innovations has, to the best of our knowledge, never been previously addressed.

The rest of this paper therefore focuses specifically on intermediary actors in relation to a particular area of grassroots innovation: community energy projects in the UK. The next section outlines the UK community energy sector, and details the methodological approaches we employed.

\section{Researching community energy intermediaries in the UK}

Small-scale, sustainable energy projects led by local communities have recently flourished in the UK. Whilst Walker identified over 500 community renewables projects existing in 2005, by 2013 the EnergyShare website - an online forum for community energy initiatives - is able to list more than 1000 active groups (Walker, 2008). Within this growing field, a very wide range of different activities are being undertaken, from small-scale renewable energy generation projects such as community-owned windfarms or solar photovoltaic cooperatives, through schemes to promote energy efficiency such as bulk-buying loft insulation, to awareness raising and behaviour change initiatives designed to encourage reductions in energy consumption (e.g. Hielscher, 2011b). The forms of innovation occurring within this grassroots field are also manifold. Whilst the specific technologies or behaviour approaches being used are often not especially novel in and of themselves, having often been developed in more mainstream settings, the fact of applying them in the community sector poses a wide-range of challenges that demand forms of 'social innovation' (Mulgan, 2006). Community energy projects thus encompass a wide range of novel sociotechnical arrangements, including the development of new ownership and funding models to ensure benefits are shared throughout communities; new approaches to support the deployment of renewable technologies at a community-scale, as well as new organisational structures to ensure community-involvement in decision-making (e.g. Hielscher et al., 2013).

Whilst community-scale action on energy dates back at least as far as the 1970s movements around alternative technology and the development of a 'soft energy path' (Lovins, 1977; Smith, 2006b), before the late-1990s much of it was dismissed as small-scale and irrelevant by mainstream energy actors. Since then, however, the 'new localism' of the New Labour Government, and the current Conservative-Liberal Democrat Coalition's policy rhetoric around the 'Big Society' have resulted in several policy initiatives designed to enhance the potential benefits of a more decentralised energy system with higher levels of community involvement and thus to try and expand the community energy sector (even if growth and expansion is not always an aim for local community energy projects themselves).

Under New Labour, for example, the 'Community Renewables Initiative' and 'Community Action for Energy' were amongst a range of measures designed to provide support for communitylevel activity on energy (Walker et al., 2007). Some of these initiatives were solely designed to boost activity within the community sector, often by providing funds to intermediary organisations in order that they could advise local community groups over the development of projects. In other cases, these initiatives were more general-purpose, inviting competitive applications from individual householders, public sector organisations (like schools) and business, as well as community groups.

More recently, under the Conservative-Liberal Democrat coalition, a significant shift has occurred away from grants and the subsidy of upfront investment costs, and towards revenueguarantee schemes to encourage new forms of 'community enterprise'. The Feed-in-Tariff, for example, provides guaranteed, above market rate payment for each unit of electricity generated from approved and certified, small-scale renewable electricity technologies. What this means for community groups is that they now have to adopt more business-like models, whereby they generate investment capital from sources other than grants. Other recent examples within this general approach model are the Green Deal for home energy efficiency measures, and the Renewable Heat Incentive - both of which are non-community group specific.

To survive within this shifting policy and funding landscape, community energy intermediaries themselves have been frequently forced to learn and adapt, often modifying and updating the support services they provide to local community energy projects. Accordingly, and building on Geels and Deuten work, it is possible to identify a wide range of different intermediaries offering a wide variety of different services within the community energy field (Geels and Deuten, 2006). Broadly speaking, three distinct 'waves' of the emergence of intermediaries in this area are discernable:

- The first wave, from the 1970s onwards, involved organisations such as the Centre for Alternative Technology or the Centre for Sustainable Energy (originally known as the Urban Centre for Appropriate Technology) who formed in support of the alternative technology movement.

- The second wave, in the late-1990s and 2000s, saw organisations such as the Energy Savings Trust and regionally-based organisations benefitting from the Community Renewables Initiative, such as Severn and Wye Energy Agency, or Thames Valley Energy Agency, emerge to manage the spending of public money in support of community energy initiatives.

- The third wave, from 2010 onwards, has seen the development of a number of independent consultants and professional service providers, such as Carbon Leapfrog (who provide legal support to community energy initiatives); looser networks for information exchange, discussion, and events, such as the Low Carbon Communities Network; as well as a growing interest in and advocacy for community energy from non-governmental organisations and think-tanks, such as Forum for the Future and ResPublica.

The result is a highly differentiated layering of organisations over time, resulting in a complex field of community energy intermediaries made up of a number of distinct organisations each with their own history, aims and objectives.

Our initial snowballing search identified 94 different intermediary actors operating across the areas of community renewables, energy efficiency and behaviour change and at both local and national scales. Further, our search highlighted that these organisations play a range of different roles, including:

- Initiating new community energy projects;

- Sharing information and developing forms of networking between local community energy groups (e.g. newsletters, seminars and conferences); 
- Providing tools (e.g. carbon calculators) and resources (e.g. good practice case studies and handbooks);

- Offering specific professional services such as legal or financial advice;

- Managing and evaluating funding programmes; and

- Interfacing with policymakers and energy companies to further develop community energy.

Drawing from this list of 94 intermediary actors, we conducted semi-structured interviews with 15 representatives from these organisations asking them about their organisation's aims and objectives with regards to community energy and their responses to past, ongoing and future developments within the community energy sector. Interviewees were selected to ensure a geographical spread throughout UK, to cover the areas of community renewables, energy efficiency and behaviour change, and to capture all of the specific roles played by intermediaries as outlined in the list above. The interviews were conducted between February and May 2011 and lasted an average of $1.5 \mathrm{~h}$. Table 1 provides details of all 15 interviews (Hielscher, 2011a).

In addition, to examine the kinds of knowledge that intermediaries were circulating about community energy, we collected 113 third party case study reports produced by intermediaries about specific local community energy projects. A systematic content analysis of these 113 case study reports was then conducted based on a coding protocol that focused on: core project details, project aims and objectives, organisational structures, sources of funding, challenges and barriers identified, lessons learned, as well as stakeholders, partnerships and networking activities mentioned (Hargreaves, 2011). Before proceeding, it is necessary to comment briefly on the somewhat ambiguous, dual-status of the data produced by this content analysis. The data is, at once, a representation of on-the-ground community energy activity produced by intermediary actors and therefore as likely to reflect the intermediary actors' aims and objectives as those of the local community energy projects themselves. Whilst, at the same time and in the absence of other comprehensive and up-to-date surveys or information about the extent and activity of the UK community energy sector, the data is also among the best available sources of information about UK community energy projects, although this is a problem we are seeking to address through other work ongoing as part of this research (e.g. Seyfang et al., 2013) As such, and of necessity, in this paper the results of the content analysis have a dual-status acting

Table 1

Table of interviewees.

\begin{tabular}{|c|c|c|}
\hline Type of intermediary actor & $\begin{array}{l}\text { Intermediary organisations } \\
\text { interviewed }\end{array}$ & $\begin{array}{l}\text { Interviewee } \\
\text { identifiers }^{\mathrm{a}}\end{array}$ \\
\hline $\begin{array}{l}\text { Government } \\
\text { departments } \\
\text { and organisations }\end{array}$ & $\begin{array}{l}\text { DECC; Scottish Government; } \\
\text { South East England } \\
\text { Development Association }\end{array}$ & G1-G4 \\
\hline National-level NGOs & $\begin{array}{l}\text { Centre for Sustainable Energy; } \\
\text { Energy Saving } \\
\text { Trust; Global Action Plan; } \\
\text { Low Carbon Communities } \\
\text { Network; Transition Network }\end{array}$ & NN1-NN5 \\
\hline $\begin{array}{l}\text { Local and regional } \\
\text { NGOs }\end{array}$ & $\begin{array}{l}\text { Community Energy Scotland; } \\
\text { Community Renewable Energy; } \\
\text { Development Trusts Association } \\
\text { Scotland; Marches Energy } \\
\text { Agency. }\end{array}$ & LN1-LN4 \\
\hline Private sector & $\begin{array}{l}\text { Good Energy; Independent } \\
\text { Consultants }\end{array}$ & P1-P2 \\
\hline
\end{tabular}

a To preserve anonymity, all interviewees have been assigned a unique identifier The letters refer to the type of intermediary actor the interviewees represent ( $G$ = Government; NN = National NGO; LN = Local/Regional NGO; P = Private Sector), and the numbers distinguish between individual interviewees. as both intermediaries' second-order reflections on community energy projects and as a direct source of information about the projects (with inevitable limitations).

The next section presents our key findings.

\section{Findings: intermediaries and intermediation in UK community energy}

Following Geels and Deuten's model, this section structures our findings according to the three key roles intermediaries are theorised to play in niche development processes: aggregation and learning (Section 4.1); establishing an institutional infrastructure (Section 4.2) and framing and coordinating local project activities (Section 4.3) (Geels and Deuten, 2006). Our findings suggest, however, that UK community energy intermediaries are increasingly playing a fourth, new role in which they are seen to broker and coordinate partnerships with actors beyond the niche. This new role is outlined in Section 4.4.

\subsection{Aggregating lessons from local community energy projects}

The first role Geels and Deuten identify for intermediaries is one of 'aggregating' lessons from across a range of local innovation projects in order to identify general and abstracted principles and lessons for the emerging niche as a whole (Geels and Deuten, 2006). Within the UK community energy sector, a key means by which intermediaries have attempted to gather and aggregate this knowledge is through the production of case studies about specific local projects. Typically just 2-3 pages long, these case studies generally include key facts about local community energy projects (e.g. name, start date, location, source(s) of funding, key activities undertaken and results achieved etc.) and often identify the 'lessons learned' by projects. For example, in our analysis of 113 of these case studies (Hargreaves, 2011), 58 explicitly identified one or more key lessons.

As Fig. 2 shows, some of the more common lessons identified in the intermediary-produced case studies included the need to generate support from the local community (present in $34 \%$ of cases) or specific lessons around financing projects (28\%) or gaining planning permission for renewables installations (26\%). Other, perhaps more abstract, lessons were also identified such as the need to persevere with local projects (7\%) or to stay aware of key policy and market developments (5\%). Perhaps the central message of this analysis, however, is that a very wide range of lessons are being identified across projects, with each individual project confronting a locally-specific set of issues and thus generating its own particular combination of lessons. This mix of different lessons would appear to make it difficult to transfer an overall package from one local project to another. On the one hand, the lessons learnt are so diverse that it is neither obvious nor automatic for other local projects to identify which ones might be applicable for them, whilst on the other hand, some lessons can be so locally-specific that they may have little wider applicability. Aggregating lessons beyond local projects and contexts would therefore seem to be far from straightforward.

Within our interviews, however, the role of these case studies in disseminating and aggregating key lessons was challenged. Some interviewees saw case studies as offering vital sources of inspiration that could give would-be project initiators ideas about what was possible and encourage them to start-up projects in their local area. The case studies served to indicate the broad areas of activity, tasks and steps involved. By contrast, others suggested they could be potentially demotivating and even disempowering because such 'success stories' offered little detail on the processes gone through, the challenges faced and the pitfalls experienced which can leave people feeling that "we can't do that here" (NN3). 


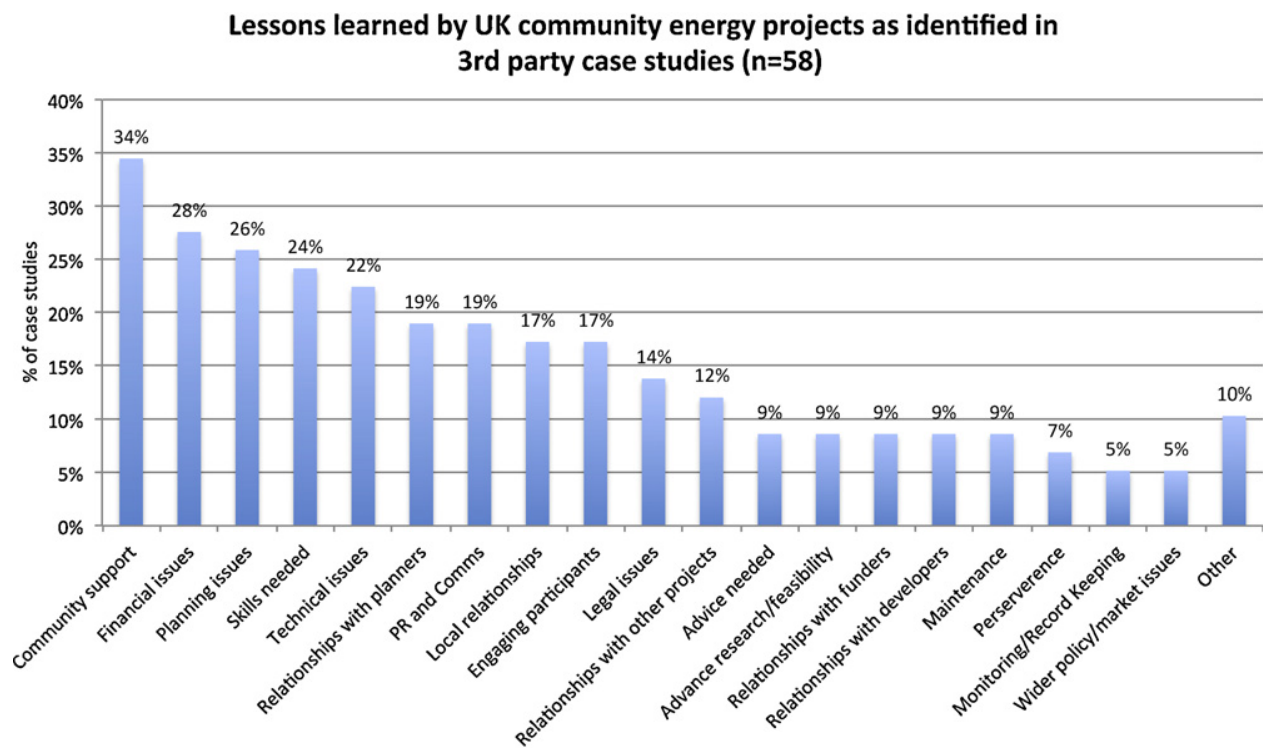

Fig. 2. Lessons learned by UK community energy projects as identified in 3rd party case studies.

Here, interviewees pointed to a more recent move beyond case studies and towards 'Toolkits', 'Handbooks' and 'How-to Guides' that provide more detail on the processes and challenges involved in developing local community energy initiatives. For example:

There was not a good set of resources to help people think through...all aspects of the project development...that told stories, rather than provided end case studies with detail around what had happened,...the process they had gone through and all the pitfalls (NN5).

Table 2 highlights several recent examples of these toolkits and handbooks. To take just one example, Community Energy Scotland's 'Community Renewable Energy Toolkit' (Community Energy Scotland, 2009) comprises over 200-pages of highly detailed information on, for example: energy, renewable energy and carbon basics; how to conduct carbon calculations; detailed chapters on a wide range of renewable and efficient technologies including heat pumps, wave and tidal power, solar photovoltaics, wind energy, biomass heating; lists of accredited installers, approaches to community consultation; details on financial models, gaining planning permission and feasibility assessments; as well as check lists to work through when getting permission for or installing new technologies.

Where case studies focus on whole projects, these toolkits and handbooks thus focus instead on specific elements of local projects (e.g. around organisational structures; funding models; communications and consultation techniques etc.) and, as a result, are beginning to identify and aggregate together some common processes. Importantly, these common processes are often then illustrated with specific and detailed case studies that

Table 2

Examples of community energy handbooks and toolkits.

\begin{tabular}{|c|c|c|}
\hline Report authors & Date & Title \\
\hline Action with Communities in Rural England, & No date & Get Generating: A Renewable Energy Guide for Rural Communities \\
\hline
\end{tabular}

for Rural Communities and National Association of Local Councils

Centre for Sustainable Energy

2009 Delivering community benefits from wind energy development: A Toolkit

Climate exchange

Climate Outreach and Information Network

Community Energy Scotland

Local United

$2010 \quad$ Oxfordshire climate change community groups handbook

No date The DIY Guide to Climate Action Groups

$2009 \quad$ Community renewable energy toolkit

20115 'diffusion packs' on:

i. Community-led hydro initiatives: Inspiring overview of hydro installations, funding and project profit management

ii. Community-led wind power: How to plan, build and own a medium or large wind turbine in your community's backyard

iii. Energy farms - anaerobic digestion: How to develop a community-led agricultural anaerobic digester

iv. Energy performance energy services company: Information and support for community household energy advisors and the development of a local supply chain for energy services v. Sustainable community loan fund: Information and finance for community loan funding to install local sustainable energy measures

Scottish Borders Counci

Methanogen Ltd.

The Environment Agency

The Highland Council and Highlands and

Islands Enterprise
No date Achieving Community Benefits from Commercial Windfarms in the Scottish Borders: A Toolkit for Communities and Windfarm Developers

2010 A toolbox guide for assessing the feasibility of an anaerobic digestion project developed for the benefit of a community or for a single farm

Hydropower: A guide for you and your community

Community Toolkit: Could your community benefit from renewable energy development? 
serve to demonstrate how these more general principles must also, and always, be employed in locally appropriate and sensitive ways.

To an extent, therefore, the recent development of these toolkits and handbooks suggests that at least some aggregation is beginning to occur and that at least some elements of local projects can be disembedded from their local context and turned into 'general, abstracted and packaged' lessons. Critically, however, several interviewees observed that the UK community energy sector, and the policy environment in which it exists, is extremely dynamic. As a result, some of these abstracted lessons (e.g. those directly linked to policy measures, or attendant financial models) may not remain valid for very long and, thus, there remains an ongoing need for close contact with and learning from local projects. This was particularly apparent in relation to recent shifts in UK energy policy that have moved attention away from the provision of grant funding to local community energy projects and towards encouraging models of 'community enterprise'. As one interviewee highlighted: "[intermediaries are only] beginning to get their head around the notion of community enterprise" (P1). In turn, this was seen as generating a need for intermediaries to reconnect with local projects in order to identify and learn new sets of key lessons themselves.

Overall, whilst our findings show that a great deal of learning is occurring across local community energy projects, our analysis is somewhat more equivocal as to whether or not this knowledge is being disembedded and aggregated together into a coherent and stable set of lessons for the community energy sector as a whole. Further still, by recognising the local and contextually-specific nature of much of the learning that is going on, it calls into question the desirability of attempting to abstract, generalise and aggregate lessons from this highly differentiated field. Some elements of project-learning appear to be common across contexts and thus seem to travel relatively well, for example around the kinds of codified knowledge and processes involved when trying to win planning permission or licenses, or when deciding on an organisational structure. Others, however, appear to remain locally embedded and contextually-specific (both spatially and temporally). As such, whilst intermediaries have been able to generate toolkits and handbooks that circulate generic and abstracted lessons, in other areas there remains no substitute for ongoing, context-specific learning that respects and preserves the diversity of local projects.

Furthermore, our analysis suggests that in addition to learning and aggregating lessons about the activities of local projects, in this dynamic policy context, community energy intermediaries themselves must also regularly (re)learn lessons about how to intermediate. This last point is particularly pertinent to the second niche role for intermediaries, that of developing institutional infrastructure.

\subsection{Establishing an institutional infrastructure for UK community energy}

The second key role that Geels and Deuten identify for intermediaries involves the creation of an institutional infrastructure that serves as a repository and forum for the storage, exchange and circulation of aggregated, global knowledge (Geels and Deuten, 2006).

Our analysis revealed a number of ways in which community energy intermediaries were already taking steps to try and build this infrastructure. In addition to the case studies, toolkits and handbooks highlighted in Section 4.1 and which facilitate 'the exchange of experiences' across local projects, a number of intermediaries sought to create web-based knowledge repositories such as the Energy Savings Trust's 'Green Communities' website (for which funding was discontinued in April 2011), the Department of Energy and Climate Change's 'Community Energy Online' website and the 'Community Energy Pathways' website created by the Community Energy Practitioners Forum. These web-based resources typically seek to bring a wide range of information and resources - such as news, databases of projects, case studies, toolkits and handbooks, online tools such as carbon footprint calculators, or checklists and step-by-step guides on how to achieve particular goals - together into a single place. Whilst extremely useful, as the example of the Energy Savings Trust's 'Green Communities' website shows, these online resources must be regularly updated and so are not necessarily easy to maintain.

Beyond these print and web-based knowledge repositories however, our interviews revealed that a key means by which intermediaries were attempting to develop an institutional infrastructure for UK community energy was through the creation of networks. Our analysis highlighted that a number of different kinds of networks exist within the community energy sector, including: networks of different local projects (e.g. the Low Carbon Communities Network; Community Powerdown; the Development Trust Association Scotland); networks of intermediary actors (e.g. the Community Energy Practitioners' Forum; Climate Challenge Fund Supporting Alliance) and even, more recently, what several interviewees described as 'networks of networks' (e.g. the Communities and Climate Action Alliance). These networks undertake a wide range of different activities, from organising events, such as the annual Low Carbon Communities Network conference, working with policy makers to design and deliver funding schemes (such as working groups to discuss how community groups can get involved in the Green Deal) and, occasionally, seeking to influence policy-decision making e.g. through responses to consultations or lobbying activities on behalf of the community energy sector.

On the face of it, therefore, these intermediary activities appear to have gone quite some way towards creating the "forums that enable (and induce) the gathering and interaction of actors, the exchange of experiences and the organisation of collective action" of which Geels and Deuten speak (Geels and Deuten, 2006, pp. 267-268). At the same time, our analysis also highlighted that there are profound difficulties and disagreements involved in undertaking them, that they have very few if any resources and are often extremely fragile, and thus that they are, currently at least, some way from providing an institutional infrastructure capable of identifying the 'shared rules' or 'emerging trajectory' for the community energy sector that strategic niche management theory suggests would be desirable.

As Fig. 3 suggests, whilst a wide range of local initiatives and activities might be classified as forms of 'community energy' this does not necessarily suggest that they have shared aims or motivations. The intermediary-produced case studies we analysed identified a wide range of different aims for community energy initiatives including: carbon reduction (mentioned in 55\% of all case studies); community development (22\%); sustainability in general (15\%), reducing fuel poverty (6\%) and improving local energy security (5\%).

Beyond these differences of aims, our interviews also highlighted differences between community energy projects as to whether or not they were intended to grow and present an alternative to the current centralised system of energy provision or whether or not they were simply designed to remain as small-scale, local solutions to particular problems. Furthermore, the groups themselves, but also intermediaries, differed as to whether they felt they should engage in radical political activism or more reformist and incremental practical action. In short, these differences and disagreements make it very difficult for intermediaries to establish 


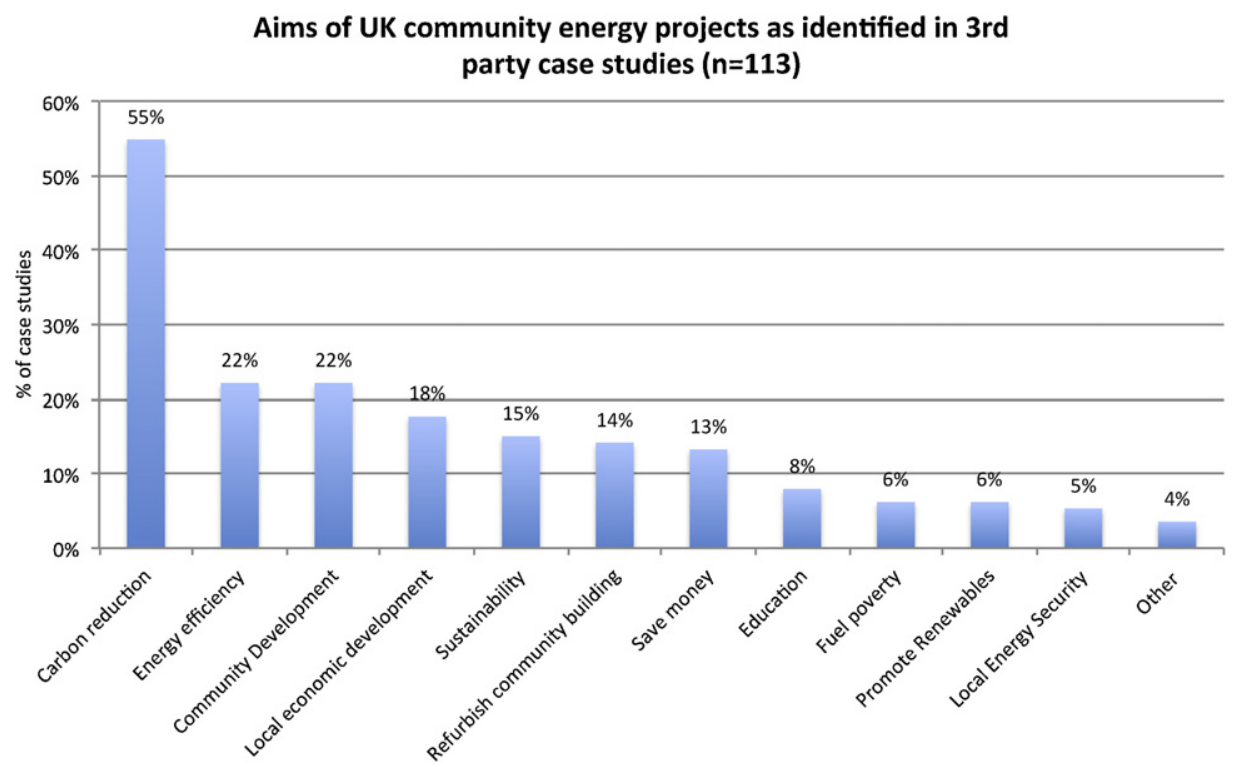

Fig. 3. Aims of UK community energy projects as identified in 3rd party case studies.

a core institutional infrastructure that adequately represents the interests of the entire community energy sector. They thus suggest a need to adapt Geels and Deuten's framework, when it is applied in this area, such that it actively incorporates and respects the diverse aims of local community energy projects (Geels and Deuten, 2006).

Attempts since 2011 to establish the Communities and Climate Action Alliance provide a good example of the sorts of difficulties intermediaries encounter here. The Department of Energy and Climate Change and other governmental departments considered the various intermediary organisations and community initiative networks as "incredibly confusing" (NN1) and thus expressed the wish of simplifying the sector and having "one organisation that we, as [the Department of Energy and Climate Change], could talk to on behalf of the communities" (NN1). The Communities and Climate Action Alliance was thus designed to be a 'network of networks' that aimed to create a "common purpose and a common voice" for the community energy sector to help generate "increased impact through more co-ordinated and coherent activity" (Communities and Climate Action Alliance, 2011). Nonetheless, our interviewees suggested that, in practice, the Communities and Climate Action Alliance struggled to find this common voice:

Within the [Communities and Climate Action Alliance]. . .I think the problem is that there is not necessarily a common voice. There are some disagreements (NN2).

Further still, there were disagreements as to whether or not the Communities and Climate Action Alliance should simply respond to the Government's existing consultations and questions or should play a more proactive role to lobby for the creation of new policies that benefitted the community energy sector. Finally, our interviewees suggested that there were real concerns within the Communities and Climate Action Alliance that, because it was set up in response to a Government request, it risked becoming a means by which Government could more closely control the community energy sector:

I think all throughout [its] development, people did not want that [responding to the Department of Energy and Climate Change] was the only thing the [Communities and Climate Action Alliance] aimed to do... then it would be very central government driven and could potentially be something that was controlling (NN1).

The Communities and Climate Action Alliance thus provides a strong example of how difficult it is to create a 'voice' that is inclusive and diverse enough to be representative of the whole community energy sector. Furthermore, it illustrates that policy attempts to simplify and impose particular strategic objectives onto this diverse field are not only extremely difficult to achieve but are also likely to encounter strong resistance.

In addition to these challenges of finding a common voice or set of aims and approaches, several interviewees highlighted that the lack of resources in this sector, as heightened in the age of austerity', means that efforts to share resources and learning and to network together were often extremely fragile. The need for intermediaries to concentrate on their own survival rather than on contributing to the development of an institutional infrastructure for the sector as a whole was of particular concern here:

What you find in any network is that the interest of any party in it to do stuff that is beneficial to the whole tends to subside once the needs of their own organisation call more loudly (NN5).

As a result, and despite a great deal of effort, our interviewees suggested that examples of co-ordinated activity between intermediaries were often very difficult to achieve, existing only "in little pockets of isolated activity" (LN2).

In summary, as with our findings on the aggregation of lessons, our findings are similarly equivocal about current intermediary efforts to generate an institutional infrastructure for the community energy sector. There are many areas where some shared infrastructure and resources do appear to exist, such as in print and web-based resources and in the efforts being put into creating networks for sharing learning and resources across the sector as a whole. At the same time, however, these efforts have not (yet) managed to create a coherent or robust institutional infrastructure within the UK community energy sector, nor have they (yet) amounted to the development of a strategic vision or shared trajectory for the sector as a whole. Moreover, the differences and disagreements that our analysis has highlighted raise questions as to the very possibility and desirability of generating a single, robust and coherent niche for the community energy sector. In this respect, just as policy efforts to simplify and generalise about 
community energy are fiercely resisted by the projects themselves, so analysts should be careful not to impose normative goals onto grassroots initiatives that may not be shared by those initiatives.

\subsection{Framing and coordinating community energy action on the ground}

For Geels and Deuten, the third key role for intermediaries is one in which they begin to frame and coordinate action inside local projects (Geels and Deuten, 2006). As Sections 4.1 and 4.2 have outlined, however, in the case of UK community energy, the processes of knowledge aggregation and establishing an institutional infrastructure are far from either straightforward or even desirable. Few clearly established lessons have been widely influential, nor has a single and coherent shared trajectory yet begun to emerge. It is perhaps expected, therefore, that this third, framing and coordinating role may prove similarly challenging.

Indeed, within our interviews it was clearly recognised that it is impossible to simply replicate success in one local project elsewhere with a 'cookie cutter type approach' (P1). Whilst there was increasing recognition that successful local projects often shared certain internal features or went through similar sorts of processes - as highlighted by the emergence of toolkits and handbooks - interviewees suggested that attention must also be paid to the local contexts in which projects emerge. Here, even if projects are internally well-designed and adopt all of the necessary features of successful projects as identified in the various handbooks, interviewees recognised that the local context may still make development difficult:

When you start looking at their ability to be replicated it is actually very difficult to see the kind of immediate replication because they've been developed in spite of everything. You would need to replicate quite a lot of activity to make that jump (NN3).

As this quotation suggests, successful projects have often had to work hard to succeed in their own local area, for example, by identifying appropriate local partners and stakeholders, aligning with the local history and culture, or by gaining support and permission from local councillors, landowners or business people etc. The challenge of framing and coordinating community energy activity on the ground thus demands that attention is paid not only to the internal content of specific local projects, but also to their surrounding context (cf. Law and Callon, 1994). This poses a set of challenges that cannot easily be reduced to readily transferable lessons or processes of the sort that can be distilled in a toolkit or handbook, for example.

Developing this theme further, several of our interviewees identified that one of the key roles they play in trying to frame and coordinate the activity of local projects is by building participant confidence and capability to persevere in the face of the many challenges they face. As the following quotation illustrates, interviewees suggested that whilst it was relatively easy to transfer technical knowledge from one place to another, the transfer of knowledge is only a small, indeed the 'easiest', part of helping local projects to succeed:

[T] he technical details. . . is the easiest part. . .[T]he hardest part to replicate is the way a community group builds its confidence and capabilities. Without that, nothing happens (LN3).

In its focus on flows of knowledge alone, therefore, Geels and Deuten's model misses out a critical part of intermediation processes, at least as they occur in the UK community energy sector (Geels and Deuten, 2006). Building confidence and capabilities, our interviewees suggested, is essential for helping local community energy projects to get going and to keep going in spite of the difficulties they face in their local area. At the same time, succeeding in this confidence-building role demands that intermediaries provide a high-level of resource-intensive support, such as face-to-face mentoring and training workshops, which have also been amongst the first things to be cutback in the current economic climate. One of our interviewees highlighted a programme his organisation had developed to try and overcome this challenge. They had created a DVD for local community energy projects that was designed to replace the need for face-to-face contact and support:

The idea behind the DVD was that it could become the expert in the room for the group, so they could watch bits of it, have a discussion about it, go back to the bits of it, look at the documentation and so forth. It was all done with a view to trying. . to take it back to a level where you could imagine a group in a room, someone would be able to understand it and then explain it to others (NN5).

At the time of writing it is too early to tell whether or not this particular initiative has been successful. Nonetheless, this example is testament to the importance our interviewees placed on acting as 'the expert in the room' for local projects to give them the confidence they need to address locally-specific challenges as and when they arise. Indeed, with this aim of acting as 'the expert in the room' in mind, some higher profile, successful local projects, such as Low Carbon West Oxford, have begun to assist other groups directly, thereby becoming a kind of intermediary themselves. In the longer term, therefore, were community energy to grow substantially, we might anticipate this kind of mutuality to become more prevalent. Until such a time, however, continued investment in intermediary organisations seems essential.

Whilst the difficulties of replicating local projects due to local contextual difficulties and the need to go beyond knowledge transfer to build the confidence and capabilities of local projects were the key issues our interviewees identified in relation to their framing and coordinating role, two further points also deserve attention here. First, that different forms of framing and coordination might be required for different parts of the UK community energy sector. Second, that community energy intermediaries themselves are not the only framing and coordinating influence on local projects.

In relation to the first point, our analysis suggested that different parts of the UK community energy sector face different pressures and challenges and may therefore require different forms of support and framing or coordination from intermediaries. In particular, one of our interviewees highlighted the occasional divisions and disconnects between projects that focus on behaviour change, improving energy efficiency, or developing renewable forms of energy. For example, reflecting on his experience in early meetings of the Community Energy Practitioners Forum, one of our interviewees suggested that there were 'completely different languages' spoken in the fields of behaviour change and community renewables projects:

They spoke a completely different language to us. They got into acronyms and policy details. It is like wading through syrup trying to understand the nuances of putting together an energy scheme... For whatever reason - maybe it was us, maybe it was them - but there was no connection (NN4).

Similarly, another interviewee argued that there could be big differences between the fields of energy efficiency and small-scale renewables in relation to setting-up community-led social enterprises. Within the field of energy efficiency, because of the design of policies such as the Green Deal that are not specific to community groups, community enterprises were often forced to compete with major energy companies (with their attendant 
marketing departments, policy teams and resources) to win funding. By contrast, in the area of small-scale renewables projects - which are often too small to attract major commercial interest community groups are competing in a 'smaller market' (NN1) and may therefore have a better chance of success. These examples suggest that different parts of the broad community energy field face quite different challenges because of different policy histories, different market structures, and different kinds of competition. As a result, different forms of framing and coordination may be required in these different areas.

Second, a key theme that emerged in our interviews was that community energy intermediaries themselves are not the only framing or coordinating influences on local community energy projects. Here - and in addition to the local contextual influences highlighted above - interviewees suggested that funders and funding programmes, central government policies, local government involvement, and increasing interest from major energy companies seeking to meet sustainable energy targets, all played major influences in shaping what local community energy projects actually do.

In particular, the current focus on reducing carbon emissions was highlighted as potentially constraining. Despite the often wide-ranging motivations, aims and objectives of local community energy projects, policy targets and funding requirements to demonstrate significant carbon savings was often highlighted as a dominant framing influence:

Unless communities can show that they can deliver stuff on carbon savings it is a bubble that could quite easily burst (NN1).

As this quotation illustrates, the manner in which local community energy projects were being framed and coordinated by these 'outside' influences - such as through the narrow lens of 'carbon reduction' (which, according to our analysis of intermediary-produced case studies is often only a small part of the wider aims and objectives of local community energy projects in any case - see Fig. 3) - was also seen as potentially risky and constraining for the success of the sector as a whole. As a result, several interviewees highlighted a fourth role that they increasingly found themselves playing that involved brokering and managing partnerships with these 'outside' influences. This fourth role is the focus of the next section (Section 4.4).

In summary, reflecting on the framing and coordinating efforts of community energy intermediaries, our analysis highlights a number of key points. First, that it is extremely difficult to directly replicate local community energy projects because of local, contextual differences. Community energy intermediaries, this point suggests, cannot therefore limit their focus to internal project development but must also consider how projects fit-in to (or try to shape/make room within) their surrounding contexts. Second, that as well as transferring 'knowledge' from one place to another, a critical challenge for community energy intermediaries is to build the confidence and capabilities of local community groups. This is a challenge that appears to be especially resource-intensive and which may not be easily reducible to readily transferable lessons. Third, our analysis suggests there may be important differences and divides within the community energy sector, such as between the sub-fields of behaviour change, energy efficiency and smallscale renewables. This further raises the possibility - as highlighted in Section 4.2 - that seeking to develop, a coherent 'community energy niche' may not be a desirable goal as it may fail to reflect the realities of community energy on the ground as different local projects often have very different aims and ambitions and can therefore face very different challenges. Fourth, and finally, the recognition that community energy intermediaries are not the only framing or coordinating influence on local community energy projects suggests that there may be a need to distinguish more closely between 'intermediaries' and wider processes of 'intermediation' which may not always be entirely deliberate or necessarily positive. Ultimately, these findings suggest the need for nuanced theoretical understandings of community energy projects and grassroots innovations that recognise that not all such innovations share the 'strategic' aims of growth and diffusion.

\subsection{Brokering and managing partnerships}

As the previous section highlighted, our analysis suggests that community energy intermediaries increasingly find themselves playing a fourth role, one of brokering and managing partnerships between local community energy projects and other actors from outside the community energy sector - particularly major energy companies.

This fourth role appeared to have deepened and taken on new significance with the policy shifts outlined earlier, such as in relation to negotiating opportunities for community groups in the Green Deal, and in addressing proposed changes to the Feed-inTariff that risked reducing the scope for community-led projects. As a result, community energy intermediaries increasingly find themselves trying to identify new sources of investment for local projects and developing new models for 'community enterprises'. While, at the same time, major energy suppliers are increasingly being forced to achieve various statutory targets, such as for the generation of electricity from renewable sources or improvements in the energy efficiency of the housing stock, and see partnerships with local community groups (which are seen as being locally trusted) as having the potential to help them achieve these targets. Further still, some interviewees suggested that partnerships with major energy companies are probably necessary if community energy initiatives do indeed desire to make a major contribution to the wider energy system as a whole:

We're going to have to find a way of marrying the community perspective with the private sector interest. Otherwise it will always be a niche activity (P1).

Despite the convergence of these factors, all suggesting a need for community-corporate partnerships, our interviewees also pointed towards "a huge, yawning cultural gap [in]. . valuebased systems" (P1) between local community energy projects and often multi-national energy companies. As a result, several of our interviewees suggested that intermediaries had an important role to play in brokering and managing these partnerships by: introducing partners to one another, helping community groups overcome any distrust and wariness of working with large companies; drawing up the terms and conditions on which partnerships are based, and in ensuring that partnerships genuinely benefit local community groups. At the same time, they recognised that undertaking these activities came with the cost (and risk) of simplifying the otherwise disparate and diverse community energy sector to make it easy for large corporate partners to see how it can help them achieve their targets.

An oft-cited example of one successful partnership was Fintry Development Trust's wind turbines. Here, the local project has negotiated a deal in which a developer provided capital funding for fifteen wind turbines, and the Development Trust can pay back the capital cost of one turbine over time through the revenue generated. Once the payback period is complete, the community will not simply own one turbine, but rather one fifteenth of the total output from all fifteen turbines. This agreement has not only helped the developer to win permission for fifteen large wind turbines, but has also helped the community both to find the capital for a major renewables project as well as providing funding 
for other local community development projects through the revenue generated. By further developing this sort of model and learning key lessons from other community-corporate partnerships, our interviewees suggested that intermediaries have a key role to play in this area.

Beyond partnerships with major energy companies, however, our interviewees also suggested that intermediaries had a potentially important role to play in lobbying policy-makers to ensure that future policy developments helped rather than hindered the community energy sector as a whole. This was recognised as very difficult to achieve, however. Whilst, the Communities and Climate Action Alliance had managed quite rapidly to find some coherence in developing a collective response to the Government's fast-track review of the Feed-in-Tariff, a few of our interviewees felt that this kind of reactive engagement with policy makers, responding to existing, rather than setting new agendas, needed to change.

For example, some interviewees suggested that, as a whole community energy still adopted a somewhat subservient mentality when engaging with policy-makers and large companies in which it was "still. . .trying to seek permission for what we want to do" (LN2) and "looking at the table and waiting for crumbs to fall off" (NN2). At the same time, however, whilst reactive responses to a common threat might be relatively easy to produce, the diversity and disagreements across the spectrum of community energy initiatives make it much harder, and call into question the desirability and appropriateness of efforts, to develop a single, proactive and coherent agenda. For these reasons, our interviewees also suggested that attempts to lobby policy makers had so far been far from successful:

What we tend to do is talk to officials...I got access to the Secretary of State every now and again, more or less when you're pouring out a cup of tea, [but] I don't think we lobby in that sense of organised campaigning to get things done (NN5).

In summary, our analysis has identified a recent shift towards a fourth major role being played by community energy intermediaries - that of brokering and managing partnerships with actors outside the community energy sector. This finding points towards a growing recognition, amongst our interviewees at least, that community energy intermediaries can no longer focus solely on internally building local community energy projects, but must actively try to work beyond the community energy sector brokering partnerships and engaging in lobbying activities - to try and shape the wider contexts (whether local, commercial or policy) in which community energy projects exist. At the same time, efforts to broker and manage these partnerships and to lobby on behalf of the community energy sector have, to date, tended to come at the cost of simplifying the sector such that it aligns with business and policy objectives that may not be shared by local projects themselves. In short, in the present policy and market context at least, intermediaries' efforts to grow, diffuse and translate local community energy projects into the mainstream, appear to come with a high price, that of reducing the diversity, dynamism and vibrancy of the community energy sector. Crucially, this is a price that many community energy activists may not wish to pay.

\section{Discussion and conclusions}

This paper started by identifying a key problem that, whilst local community-led sustainability initiatives may be critical in developing solutions to sustainability problems, these same 'grassroots innovations' (Seyfang and Smith, 2007) also often face profound challenges in simply surviving, let alone in growing and diffusing more widely. Within the literature on strategic niche management so-called intermediary actors are highlighted as important in helping small-scale, radical innovations to scale-up and form robust and coherent niches capable of challenging and potentially replacing currently mainstream and unsustainable systems of provision (e.g. Geels and Deuten, 2006). Accordingly, drawing on new empirical evidence, this paper has examined the roles played by intermediary actors in relation to a specific area of grassroots innovation - UK community energy.

Geels and Deuten suggest that intermediaries play three key roles in helping to build robust niches: aggregating lessons from across multiple local projects, establishing an institutional infrastructure for the innovation niche as a whole, and framing and coordinating action on the ground in local projects (Geels and Deuten, 2006). In relation to UK community energy, however, our analysis has significantly problematised each of these three roles, as well as identifying a new, fourth role that appears to be of increasing importance - that of brokering and managing partnerships with actors from 'outside' the community energy sector. Further still, our analysis has called into question the implication within strategic niche management that all innovations should aim for growth, diffusion and mainstreaming - suggesting that, in some instances at least, it may be inappropriate to apply strategic niche management to grassroots innovations in an unadapted form. Whilst thinking about community energy as a niche involving diverse experimentation and innovation in sustainable energy may be appropriate conceptually, we therefore conclude that forcing analysis through the expectation of unproblematic standardisation, diffusion and growth is dubious.

Specifically, our analysis has shown, first, that learning must be seen as a constant and ongoing process both for local community energy projects and for intermediaries themselves. Second that building institutional infrastructures is extremely difficult when diverse interests are in play. Third, that framing and coordinating local projects involves lots of resource intensive work to build confidence and capabilities and to respond to and attempt to shape local and policy contexts. Fourth, that community energy intermediaries are increasingly engaging in a process of forging partnerships and lobbying with the wider social world.

Overall, therefore, and despite the best efforts of community energy intermediaries who operate in extremely difficult circumstances, we have found little evidence, to date, that community energy intermediaries have managed to build a coherent, robust and strategic community energy niche (Walker et al., 2006). At the same time, however, the differences in aims, approaches, ideologies and local contextual situations that the community energy sector spans call into question whether the development of a single, robust and coherent community niche is either an achievable or even desirable goal. In addition to local community energy projects themselves differing markedly in their aims, ideologies and approaches, so too does a dynamic policy and market context place different pressures on different parts of the broad community energy field (e.g. around behaviour change, energy efficiency and community renewables). This suggests that different kinds of intermediation might be required in different areas to achieve different ends.

This dynamism and diversity problematises the strategic and growth-oriented thrust of strategic niche management approaches when they are applied to grassroots innovations such as community energy projects. Here, Seyfang and Smith draw an important distinction between strategic niches which seek wider scale transformation, and simple niches which do not seek wider regime change but rather aim to offer mutual support for often poorly resourced grassroots initiatives (Seyfang and Smith, 2007). Our analysis suggests that the UK community energy sector may currently contain aspects of both simple and strategic niches existing side-by-side. In this respect, niches for grassroots 
innovations may differ considerably from niches concerned with the development of specific technologies and their trajectories of development (such as those around which the strategic niche management literature emerged originally) and are thus likely to demand quite different forms of support, intermediation and theorising.

For community energy, as for many forms of grassroots innovation, our analysis suggests that intermediation may be more about opening up space in different contexts (whether local, policy, market, social etc.) for new and diverse kinds of activity, rather than about developing a single successful approach or a strategic vision for its growth and diffusion. As a result, grassroots intermediation seems likely to require different kinds of support. For example: support that recognises and respects a diversity of aims and approaches as a reality of grassroots innovations and supports forms of intermediation that respond to this (e.g. through face-to-face mutual learning, rather than through attempts to codify and standardise action on the ground); support that enables the development of a flexible and locally devolved institutional infrastructure that is not expected to speak with a single, common or coherent voice; and support that develops and empowers the wider space for grassroots innovations by addressing the distortions and structural inequalities that exist in current policy and market contexts.

In conclusion, whilst we have found Geels and Deuten's model to be very helpful in outlining the core roles played by intermediaries, our findings illustrate that care and sensitivity needs to be taken when transposing theories of transition and strategic niche management to grassroots innovations (Geels and Deuten, 2006). Grassroots innovations encompass a very wide range of different aims, objectives and ideologies in ways that challenge simplistic notions and theories of innovation. It is critical, therefore, both that future research on grassroots innovations illuminates and respects this complexity, and that theoretical approaches are applied and developed in ways that do not do violence to grassroots initiatives that are striving hard to generate sustainable solutions in spite of everything.

\section{Acknowledgements}

The authors would like to thank Lucie Middlemiss as well as participants at the international workshop on 'Grassroots Innovations' (University of Sussex, May 2012) and at the RGS-IBG Annual conference session on 'Energy and Communities' (Edinburgh, July 2012) for helpful comments on earlier drafts of this article. This research would not have been possible without the generous assistance of the interviewees or of the Engineering and Physical Sciences Research Council and EdF Energy funded 'People Energy Buildings' programme (Grant ref: F/00 204/AM).

\section{References}

Avelino, F., Kunze, I., 2009. Exploring the transition potential of the ecovillage movement. In: European Conference on Sustainability Transitions: Dynamics and Governance of Transitions to Sustainability, 4-5 June, Amsterdam, The Netherlands.

Bos, B., Grin, J., 2008. 'Doing' reflexive modernization in pig husbandry: the hard work of changing the course of a river. Science Technology \& Human Values 33 (4), 480-507.

Communities and Climate Action Alliance (2011) Creating Low Carbon Communities: A Report on Key Issues Arising at the 'Communities and Climate Action' Conference. London, Communities and Climate Action Alliance.

Community Energy Scotland (2009) Community Renewable Energy Toolkit. Edinburgh, Community Energy Scotland/The Scottish Government.

Elzen, B., Geels, F.W., Green, K. (Eds.), 2004. System Innovation and the Transition to Sustainability: Theory, Evidence and Policy. Edward Elgar, Cheltenham.

Elzen, B., Geels, F.W., Leeuwis, C., Van Mierlo, B., 2011. Normative contestation in transitions 'in the making': animal welfare concerns and system innovation in pig husbandry. Research Policy 40, 263-275.
Geels, F.W., 2005. Technological Transitions and System Innovations: A Co-evolutionary and Socio-Technical Analysis. Edward Elgar, Cheltenham.

Geels, F., Deuten, J.J., 2006. Local and global dynamics in technological development: a socio-cognitive perspective on knowledge flows and lessons from reinforced concrete. Science and Public Policy 33 (4), 265-275.

Geels, F., Raven, R., 2006. Non-linearity and expectations in niche-development trajectories: ups and downs in Dutch biogas development (1973-2003). Technological Analysis and Strategic Management 18 (3/4), 375-392.

Geels, F.W., Verhees, B., 2011. Cultural legitimacy and framing struggles in innovation journeys: a cultural-performative perspective and a case study of Dutch nuclear energy (1945-1986). Technological Forecasting \& Social Change 78 (6), 910-930.

Hargreaves, T., 2011. 3rd Party Case Study Content Analysis: Initial Results. Internal Report for the Community Innovation for Sustainable Energy Project. University of East Anglia, Norwich.

Hegger, D.L.T., Van Vliet, J., Van Vliet, B., 2007. Niche management and its contribution to regime change: the case of innovation in sanitation. Technological Analysis and Strategic Management 19 (6), 729-746.

Hielscher, S. (2011a). Analysis of first round of intermediary interviews: initial results. Internal Report for the Community Innovation for Sustainable Energy Project. Brighton, University of Sussex.

Hielscher, S. (2011b). Community Energy in the UK: A Review of the Research Literature. Working Paper for the Community Innovation for Sustainable Energy Project. Online at: http://grassrootsinnovations.files.wordpress.com/2012/03/ cise-literature-review.pdf.

Hielscher, S., Seyfang, G., Smith, A., 2013. Grassroots innovations for sustainable energy: exploring niche development processes among community energy initiatives. In: Brown, H., Cohen, M., Vergragt, P. (Eds.), Innovations in Sustainable Consumption: New Economics, Socio-technical Transitions, and Social Practices. Edward Elgar, Cheltenham.

Hoogma, R., Kemp, R., Schot, J., Truffer, B., 2002. Experimenting for Sustainable Transport. Spon Press, London.

Howells, J., 2006. Intermediation and the role of intermediaries in innovation Research Policy 35, 715-728.

Kemp, R., Schot, J., Hoogma, R., 1998. Regime shifts to sustainability through processes of niche formation. The Approach of Strategic Niche Management Technology Analysis \& Strategic Management 10, 175-198.

Kemp, R., Rip, A., Schot, J., 2001. Constructing transition paths through the management of niches. In: Garud, R., Karnoe, P. (Eds.), Path Dependence and Creation. Lawrence Erlbaum Associates, Mahwah, NJ, pp. 269-299.

Law, J., Callon, M., 1994. The Life and Death of an Aircraft: A Network Analysis of Technical Change. In: Bijker, W.E., Law, J. (Eds.), Shaping Technology/Building Society: Studies in Sociotechnical Change. MIT Press, Cambridge, MA, pp. $21-$ 52 .

Longhurst, N., 2012. The Totnes Pound: a grassroots experimental niche. In: Davies, A. (Ed.), Enterprising Communities: Grassroots Sustainability Innovations. Emerald, Bingley.

Lovins, A., 1977. Soft Energy Paths: Toward a Durable Peace. Friends of the Earth International, San Francisco.

Medd, W., Marvin, S., 2008. Making water work: intermediating between regional strategy and local practice. Environment and Planning D: Society and Space 26 (2), 280-299.

Moss, T., 2009. Intermediaries and the governance of sociotechnical networks in transition. Environment and Planning A 41 (6), 1480-1495.

Mulgan, G., 2006. The process of social innovation. Innovations 2006 (Spring), 145 162.

Raven, R.P.J.M., 2006. Towards alternative trajectories? Reconfigurations in the Dutch electricity regime. Research Policy 35 (4), 581-595.

Raven, R.P.J.M., 2007. Niche accumulation and hybridisation strategies in transition processes towards a sustainable energy system: an assessment of differences and pitfalls. Energy Policy 35 (4), 2390-2400.

Raven, R.P.J.M., Heiskanen, E., Lovio, R., Hodson, M., Brohmann, B., 2008. The contribution of local experiments and negotiation processes to field-level learning in emerging (Niche) technologies: meta-analysis of 27 new energy projects in Europe. Bulletin of Science Technology \& Society 28 (6), 464477.

Raven, R.P.J.M., Van Den Bosch, S., Weterings, R., 2010. Transitions and strategic niche management: towards a competence kit for practitioners. International Journal of Technology Management 51 (1), 57-74.

Seyfang, G., 2009. The New Economics of Sustainable Consumption: Seeds of Change. Palgrave MacMillan, Basingstoke.

Seyfang, G., Smith, A., 2007. Grassroots innovations for sustainable development: towards a new research and policy agenda. Environmental Politics 16 (4), 584 603.

Seyfang, G., Park, J., Smith, A., 2013. A Thousand Flowers Blooming? An examination of community energy in the UK. Energy Policy, in press.

Smith, A., 2006a. Green niches in sustainable development: the case of organic food in the United Kingdom. Environment and Planning C 24, 439-458.

Smith, A., 2006b. Niche-based approaches to sustainable development: radical activists versus strategic managers. In: Bauknecht, D., Kemp, R., Voss, J.-P. (Eds.), Sustainability and Reflexive Governance. Edward Elgar, Camberley.

Smith, A., 2007. Translating sustainabilities between green niches and socio-technical regimes. Technology Analysis \& Strategic Management 19 (4), 427-434.

Smith, A., Voss, J.-P., Grin, J., 2010. Innovation studies and sustainability transitions: the allure of the multi-level perspective and its challenges. Research Policy 39, 435-448. 
Truffer, B., 2003. User-led innovation processes: the development of professional car sharing by environmentally concerned citizens. Innovation 16 (2), 139-154.

Walker, G., 2008. What are the barriers and incentives for community-owned means of energy production and use? Energy Policy 36, 4401-4405.

Walker, G., Devine-Wright, P., Evans, B., 2006. Embedding socio-technical innovation: niche management and community-based localism in renewable energy policy in the UK. In: The Future of Science, Technology and Innovation Policy Conference, SPRU, University of Sussex, Brighton, September 2006.

Walker, G., Hunter, S., Devine-Wright, P., Evans, B., Fay, H., 2007. Harnessing community energies: explaining and evaluating community-based localism in renewable energy policy in the UK. Global Environmental Politics 7 (2), $64-82$. 